\title{
Prediction of the Rupture of Circular Sections of Reinforced Concrete and Fiber Reinforced Concrete
}

\author{
A. Adjrad ${ }^{1,2), *}\left(\mathbb{0}\right.$, Y. Bouafia $^{1,2)}$, M. S. Kachi ${ }^{1,2)}$, and F. Ghazi ${ }^{1,2)}$
}

(Received January 28, 2015, Accepted March 4, 2016, Published online March 18, 2016)

\begin{abstract}
As part of this study, has been developed a numerical method which allows to establish abacuses connecting the normal force with bending moment for a circular section and therefore to predict the rupture of this type of section. This may be for reinforced concrete (traditional steel) or concrete reinforced with steel fibers. The numerical simulation was performed in nonlinear elasticity up to exhaustion of the bearing capacity of the section. The rupture modes considered occur by plasticization of the steel or rupture of the concrete (under compressive stresses or tensile stresses). Regarding the fiber-reinforced concrete, the rupture occurs, usually, by tearing of the fibers. The behavior laws of the different materials (concrete and steel) correspond to the real behavior. The influence of several parameters was investigated, namely; diameter of the section, concrete strength, type of steel, percentage of reinforcement and contribution of concrete in tension between two successive cracks of bending. A comparison was made with the behavior of a section considering the conventional diagrams of materials; provided by the BAEL rules. A second comparative study was performed for fibers reinforced section.
\end{abstract}

Keywords: reinforced concrete, fiber reinforced concrete, circular section, abacuses, numerical simulation, bearing capacity.

\section{List of Symbols}

$\mathrm{A}_{\mathrm{ai}} \quad$ Cross-sectional area of the steel bar of order $\mathrm{i}$

bj Base width of the trapezium of order $\mathrm{j}$

D Section diameter

$\mathrm{d}^{\prime} \quad$ Concrete cover of reinforcement

$\mathrm{E}_{\mathrm{a}} \quad$ Young modulus of steel

$\mathrm{E}_{\mathrm{bo}}$ The current value of the elastic modulus of the concrete

$\mathrm{f}_{\mathrm{cj}} \quad$ Compressive strength of concrete at the age $\mathrm{j}$

$\mathrm{f}_{\mathrm{tj}} \quad$ Tensile strength of concrete

I Moment of inertia of the section

$\mathrm{k}_{\mathrm{b}} \quad$ Parameter adjusting the ascending branch of the Sargin law

$k_{\mathrm{b}}^{\prime} \quad$ Parameter adjusting the decreasing branch of the Sargin law

$\mathrm{L}_{\mathrm{f}} \quad$ Fiber's length

$\mathrm{M} \quad$ Bending moment

$\mathrm{M}_{\text {int }}$ Internal bending moment

$\mathrm{N} \quad$ Axial force

$\mathrm{N}_{\text {int }}$ Internal axial force
$\mathrm{N}_{\mathrm{bt}} \quad$ Number of trapezium

$\mathrm{Ne} \quad$ Number of steel bars

$\mathrm{S}$ Cross-sectional area of the concrete section

$\mathrm{y}_{\mathrm{ai}} \quad$ Ordinate of steel bar of order $\mathrm{i}$

$y_{j} \quad$ Ordinate of the base of the trapezium of order $j$

w Percentage of the fibers

$\delta$ The axial strain

$\delta \omega \quad$ The curvature

$\varepsilon_{\mathrm{ai}} \quad$ The current value of deformation of steel

$\varepsilon_{\mathrm{cu}} \quad$ Deformation at rupture of the concrete in compression

$\varepsilon_{\mathrm{e}} \quad$ Deformation of the yield strength

$\varepsilon_{0} \quad$ Deformation corresponding to fcj

$\varepsilon_{\mathrm{rt}}$ Deformation corresponding to the yielding of the most tense steel

$\varepsilon_{\mathrm{u}} \quad$ Ultimate deformation of steel

$\phi_{\mathrm{a}} \quad$ Diameter of steel bars

$\gamma \quad$ Angle between two successive bars

$\theta(j)$ Angle between the end of the base of the trapezium of order $\mathrm{j}$ with the vertical

$\sigma_{\mathrm{e}} \quad$ Yield stress of the steel

$\sigma_{\mathrm{r}} \quad$ The rupture stress of steels

\section{Introduction}

The calculation of reinforced concrete sections is a well known and understood problem (Bonet et al. 2006; Daunys and Rimovkis 2006; Choa and Kwonb 2008; Liang and Fragomeni 2009; Ronagh and Baji 2014; Ren et al. 2015). In

\footnotetext{
${ }^{1)}$ University “Mouloud Mammeri” of Tizi-Ouzou, 15000 Tizi Ouzou, Algeria.

*Corresponding Author; E-mail: adjradarezki@gmail.com

${ }^{2)}$ Laboratory "LaMoMS” (Experimental and Numerical

Modeling of Materials and Structures of Civil

Engineering), University "Mouloud Mammeri” of Tizi-

Ouzou, 15000 Tizi Ouzou, Algeria.

Copyright $\odot$ The Author(s) 2016. This article is published

with open access at Springerlink.com
} 
the particular case of circular sections, the problem is complex. Due to the provision of reinforcement and concrete, the circular sections have substantially the same geometric characteristics in all directions. Therefore, the calculation remains complicated given the position of the armatures which induces several unknown in the expression of the equilibrium equations in the case of a composed bending (Kachi et al. 2014).

Also in the case of fiber reinforced concrete, several studies were conducted in recent years to characterize the behavior of this type of composite, but the problem becomes even more complicated in the case of circular sections subject to combined loads.

Experimental and finite element analysis, in ultimate behavior, on the steel fiber-reinforced concrete beams has been made by Özcan et al. (2009); authors modeled beams using nonlinear properties of materials taken from the experimental study until the ultimate failure cracks. In this study, steel fibers "Dramix-RC-80/0.60-mm" were used as additives in concrete with four different dosages of 30,40 , 50 and $60 \mathrm{~kg} / \mathrm{m}^{3}$. The finite element analysis was performed by using the ANSYS program. Results from numerical modeling and experimental analysis are compared to each other, it followed that there is a good agreement between the results of finite element analysis and experimental behavior.

An experimental program was conducted by Ding et al. (2012); the objective was to investigate the influence of steel fibers and the combined effect of fibers and stirrups on the beams deflection and cracking. This study also examined the feasibility of applying the modified compression field theory (MCFT) for the suitable assessment of combined load in fiber and steel rebar reinforced concrete beams. The authors noted that the combined use of stirrups and steel fibers shows great positive composite effect on shear load-carrying capacity, energy absorption capacity and toughness of beams subjected to shear and bending. Additionally, they proposed a new equation of modified compression field theory for fiber reinforced concrete in which cracked fiber concrete is treated as a new material with its own stress-strain characteristics.

Islam and Alam (2013) conducted a study to evaluate the shear strength for steel fiber reinforced concrete beams in a database that is extensive experimental results of 222 specimens with no stirrups. The results of this study showed that the recommended empirical equations were best suited to assess the shear strength of SFRC beams more accurately as compared to those obtained by the previously developed models. The authors concluded that the prediction models of SFRC, suggested by the various studies, were mostly complex and confined to non-linear regression equations.

In another study, six full-scale prestressed concrete I-beams with steel fibers were tested to failure by Tadepalli et al. (2015); the main objective of this study was to determine effects of steel fiber dosage on the shear and flexural modes of beam failure. The beams were subjected to concentrated vertical loads up to their maximum shear or moment capacity. Based on experimental observations, the authors found that the I-beams shear capacity was significantly increased due to the addition of steel fibers in the concrete. The study also showed a complete replacement of conventional shear reinforcement with steel fibers.

On the other hand, Sorensen et al. (2014) presented investigation findings of the fiber content variations in concrete being discharged from a ready-mix truck at the construction site and its effect on the behavior of fiber concrete. The type of steel fiber used in this study consists of fibers with hooked ends that were commonly used in world for decades. Based on the test results and observations, authors concluded that adjustments in batching procedures may be advisable regarding steel fiber mixing routines.

In practice, the calculation of longitudinal reinforcement is often conducted according to the principles of the current regulations, BAEL (Rules: BAEL91 99) and Eurocode2 (Eurocode2, Part 1-1 1999), considering the steel uniformly distributed over the entire section of the concrete and in the case of a normal effort of compression. The normal tensile stress was not considered and the contribution of tense concrete between the cracks is neglected. Then just ignore the tense concrete to remove physical discontinuities corresponding to cracks.

When taking into account the contribution of tense concrete between the cracks, describe the behavior of the element becomes complex considering the stress distribution. A global behavior of the element is then assumed which can be represented by the characterizing each section between two successive fissures by the behavior of an average section, representative of the entire cracking phenomenon.

The objective of this study is the development of numerical methods to simulate the non-linear behavior until rupture taking into account the tense concrete contribution, between two successive fissures. It considers reinforced concrete or fiber concrete in case of circular sections subjected to composed bending. Algorithms are then developed to calculate internal deformations from the forces applied. This has allowed us to establish abacuses giving the reinforcement section based on external forces applied.

For the compression behavior of concrete, the Sargin law is adopted. This allows us to adjust the parameters $\mathrm{k}_{\mathrm{b}}$ and $k_{\mathrm{b}}^{\prime}$ to the experimental curve (Rules: BAEL91 99). The contribution of tense and cracked concrete is made according to a parabolic law proposed by Grelat (1978).

The behavior of the fiber concrete was taken into account according to the model proposed by Bouafia et al. (2002, 2000). A comparison was made with the behavior of a section considering the conventional diagrams of materials (provided by the BAEL). A second comparative study was performed by using a section armed with fiber.

\section{Position of the Problem: Hypothesis}

In linear elasticity, the calculation of the deformation $(\delta \mathrm{u}$, $\delta w)$ developed by efforts $(\mathrm{N}, \mathrm{M})$ do not present difficulty and this from traditional relations of materials strength.

By cons in nonlinear elasticity, it is easy to calculate the forces developed by the given deformations, but there is no 
direct method for calculating the deformations starting from the given efforts. Thus the use of numerical methods is essential.

The present study fits into this framework. It acts to develop software to simulate the average behavior of a beam area in nonlinear elasticity until rupture. This area is defined as a section having a bending crack. The average behavior of this element is considered taking into account the contribution of the tensioned concrete between two successive cracks.

The studied reinforced concrete section is circular form and subjected to the composed bending. The study was carried out according to the hypothesis of small deformations taking into account the non-linear elastic behavior of materials. The Longitudinal strain at a point of the transverse section is governed by the plane sections conservation law and it was assumed a perfect adherence between steel and the concrete.

This study is conducted to the scale of a section; the effect of the slenderness in the case of column will be taken into account in the case of the structure study which will be the object of second part of this work.

Taking into account these hypotheses, the longitudinal deformation $\varepsilon$ is a linear function of the transverse ordinate (y) and is takes on the form by Eq. (1).

$$
\varepsilon=\delta u+\delta w \cdot y .
$$

\section{Modeling of the Circular Section}

\subsection{Discretization of the Concrete Section}

The concrete section was considered as a succession of trapeziums. Each trapezium was defined by the dimensions of its lower and upper base $\left(b_{j}, b_{j+1}\right)$ and their ordinates $\left(y_{j}\right.$, $y_{j+1}$ ), relative to the reference axis passing through the center of gravity of the section (Kachi et al. 2014), see Fig. 1.

The integration process is numerical, it is necessary to express the widths and the ordinates of the trapeziums consistent with the numerical calculation relations.

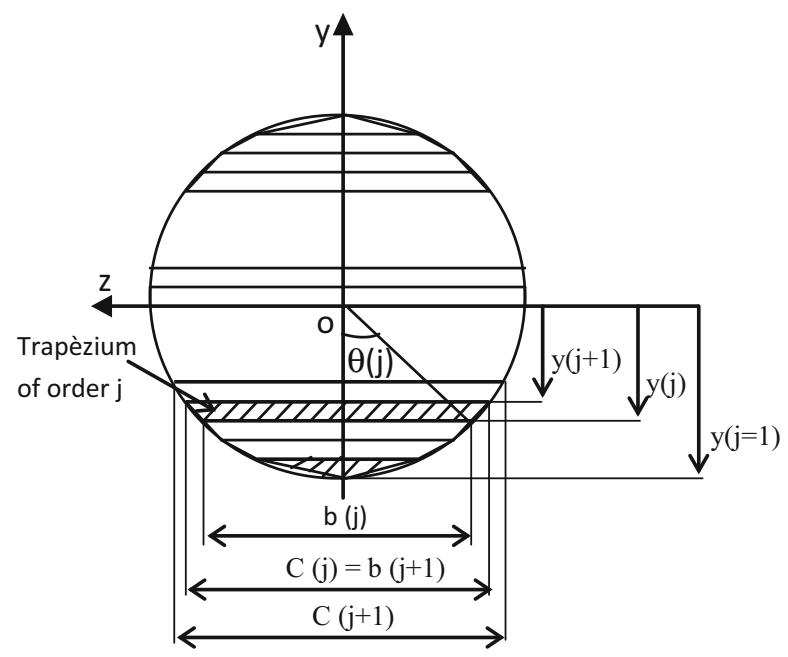

Fig. 1 Concrete section modeling.
Hence for the trapezium of order $j$; the ordinate and the width of the base are expressed respectively by Eqs. (2) and (3). The trapezium width at an ordinate $y(j+1)$ is given by Eq. (4).

$$
\begin{aligned}
& y(j)=(D(j-1) / N e)-\frac{D}{2} \\
& b(j)=D \sin \theta(j) \\
& C(j)=b(j+1)
\end{aligned}
$$

where $\theta(j)=\operatorname{arcos} \frac{|y(j)|}{D / 2}$.

\subsection{Definition of the Position of the Bars}

The section of each bar is concentrated at its center of gravity; it is indicated by its ordinate on the y-axis (see Fig. 2). For a bar of the order i, its ordinate is calculated by Eq. (5).

$$
y_{a}(i)=-\left(D / 2-\mathrm{d}^{\prime}\right) \cos ((i-1) \cdot \gamma)
$$

where $\gamma=\frac{2 \Pi}{N_{b t}}$.

\section{Calculation of Internal Forces}

The stress at a point of the section is related to the deformation by the corresponding material behavior law; $\sigma=\varphi(\varepsilon)$ see Fig. 3. The value of the function $\varphi(\varepsilon)$ was considered zero beyond the compression and tension strength material, respectively for deformations $\varepsilon_{c u}$ and $\varepsilon_{r t}$.

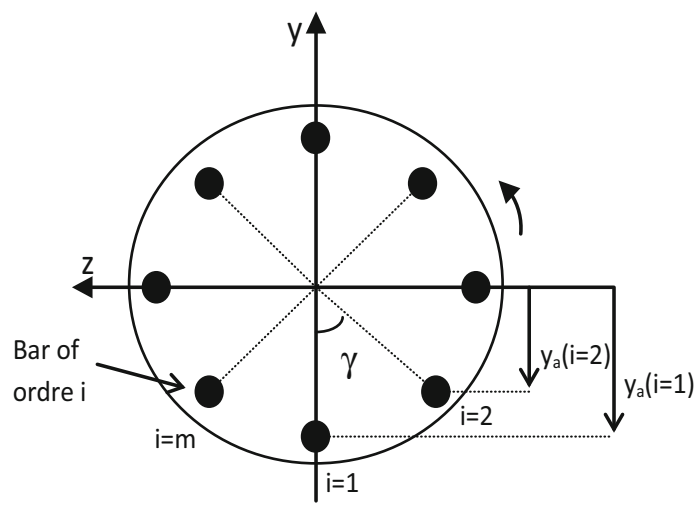

Fig. 2 Bars disposition in the section.

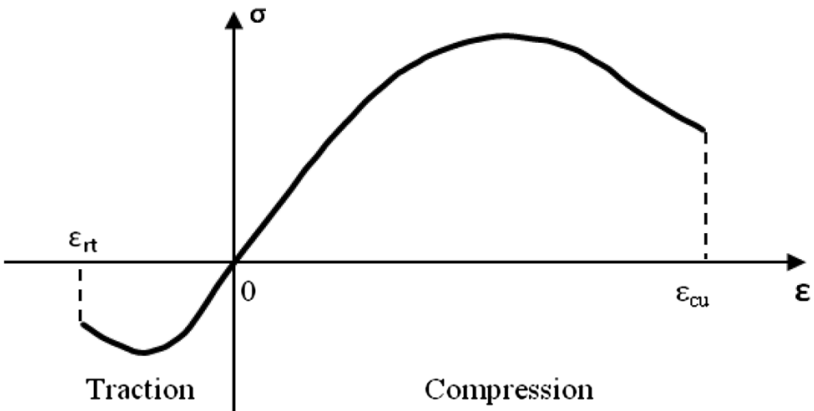

Fig. 3 Behavior material law representation. 


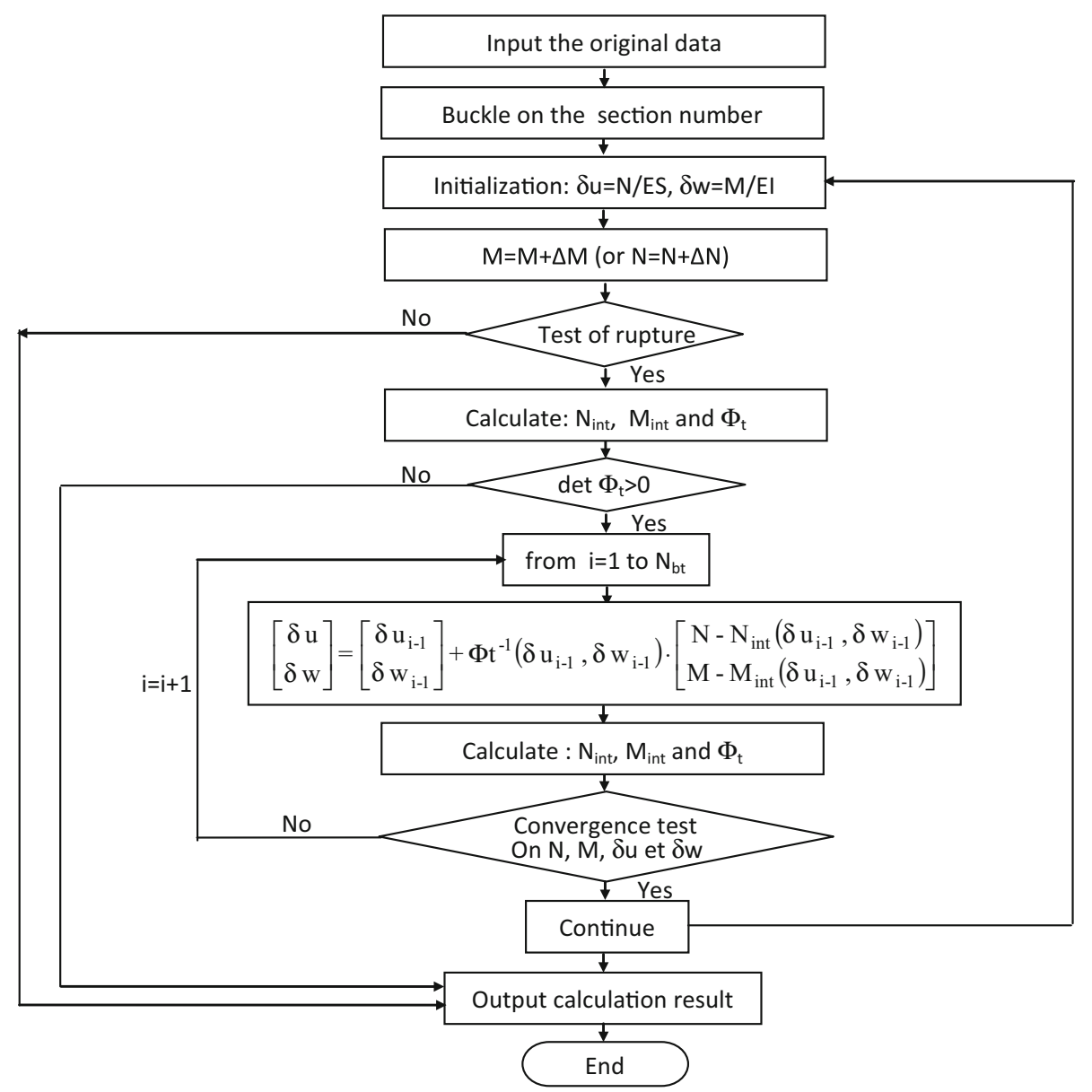

Fig. 4 Calculus method flowchart for loading curves establishment.

The calculation was then carried out in the nonlinear elasticity; taking into account the actual behavior of the various materials, some details are given in (Bouafia et al. 2000, Adjrad et al. 2015). The internal efforts $\left(N_{i n t}, M_{i n t}\right)$ developed by the deformations $(\delta u, \delta w)$ are related by the following formulas (Eq. (6)):

$$
\left\{\begin{array}{l}
N_{\text {int }}=\iint \sigma \cdot d y \cdot d z=\iint \varphi(\delta u+\delta w \cdot y) \cdot d y \cdot d z \\
M_{\text {int }}=\iint \sigma \cdot y \cdot d y \cdot d z=\iint \varphi(\delta u+\delta w \cdot y) \cdot y \cdot d y \cdot d z
\end{array}\right.
$$

While noting by $b(y)$ the section width to an ordinate $y$, then the Eq. (6) became:

$$
\left\{\begin{array}{l}
N_{i n t}=\iint \varphi(\delta u+\delta w \cdot y) \cdot b(y) \cdot d y \\
M_{\text {int }}=\iint \varphi(\delta u+\delta w \cdot y) \cdot y \cdot b(y) \cdot d y
\end{array}\right.
$$

The Eq. (7) can be written in the matrix form as follows:

$$
\left[\begin{array}{l}
N_{\text {int }} \\
M_{\text {int }}
\end{array}\right](\delta u, \delta w)=\int \varphi(\delta u+\delta w \cdot y)\left[\begin{array}{l}
1 \\
y
\end{array}\right] \cdot b(y) \cdot d(y)
$$

\section{Practical Calculation of Internal Forces}

\subsection{In the Concrete and the Fiber Concrete}

Taking into account the Eq. (1), the relationship (Eq. (8)) is rewritten in the following form (Eq. (9)); this one gives the internal forces in concrete and in the fiber concrete.

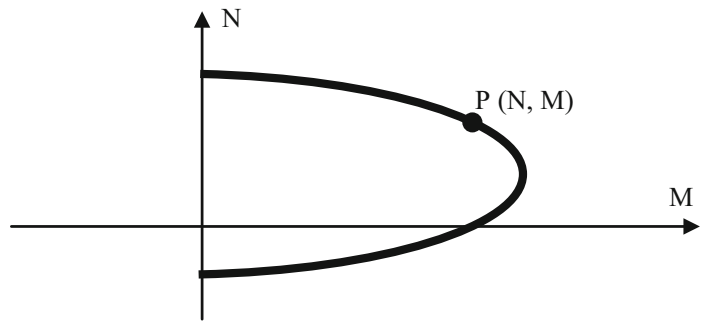

Fig. 5 Resistance boundary curve appearance.

$$
\left[\begin{array}{l}
N_{\text {int }} \\
M_{\text {int }}
\end{array}\right](\delta u, \delta w)=\int\left[\begin{array}{l}
1 \\
y
\end{array}\right] \cdot \varphi_{b}(\varepsilon) \cdot b(y) \cdot d(y)
$$

In the trapezium of order $j$, integration intervals, corresponding to each segment of the concrete constitutive law, are then defined by boundaries whose calculation involves comparing trapezium extreme fibers deformations at the order $j$ of ordinate $y_{j}, y_{j+1}$ in the particular strain of the concrete behavior law. These deformations are given by the following expressions:

$$
\varepsilon_{j}=\delta u+\delta w \cdot y_{j} \quad \text { and } \quad \varepsilon_{j+1}=\delta u+\delta w \cdot y_{j+1}
$$

\subsection{In the Reinforcing Bar}

Similarly, the reinforcement bar strain $\varepsilon_{i}$, at order $i$, is compared to the particular strain of steel behavior law that corresponds to it in order to define the term $\varphi$ corresponding to the strain $\varepsilon$. 


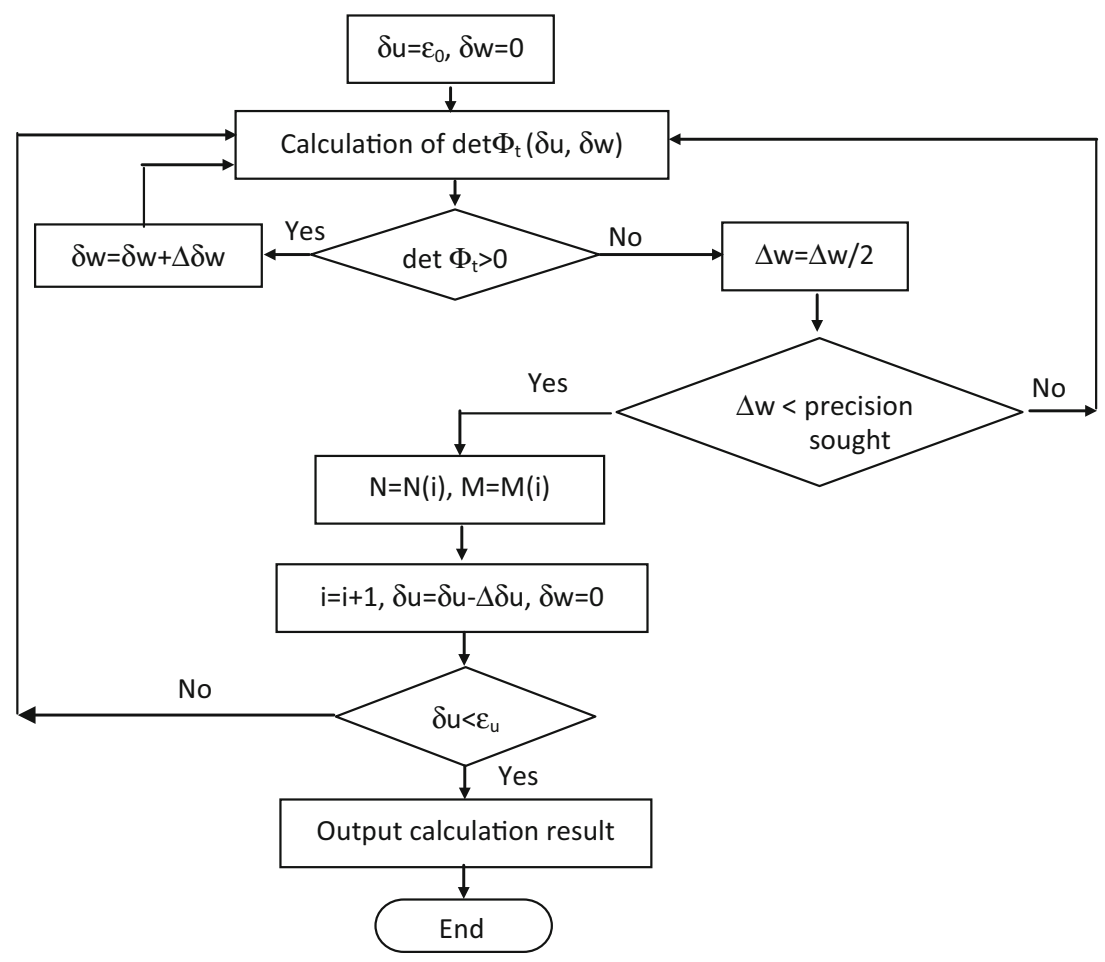

Fig. 6 Boundary curve establishment flowchart.

Table 1 Characteristics of concrete mechanical properties; C25 and C50.

\begin{tabular}{|c|c|c|c|c|c|c|c|}
\hline \multirow{2}{*}{$\begin{array}{c}f_{c j} \\
(\mathrm{MPa})\end{array}$} & \multirow{2}{*}{$\begin{array}{c}f_{t j} \\
(\mathrm{MPa})\end{array}$} & \multirow{2}{*}{$\begin{array}{c}E_{b o} \\
(\mathrm{MPa})\end{array}$} & \multicolumn{2}{|c|}{ Parameter of the Sargin law } & \multirow[t]{2}{*}{$\varepsilon_{r t}$} & \multirow[t]{2}{*}{$\varepsilon_{0}$} & \multirow[t]{2}{*}{$\varepsilon_{c u}$} \\
\hline & & & $K_{b}$ & $k_{b}^{\prime}$ & & & \\
\hline 25 & 2.1 & 32,164 & 2.316 & 1.316 & -0.05 & 0.018 & 0.0035 \\
\hline 50 & 3.6 & 40,524 & 1.378 & 0.378 & -0.05 & 0.017 & 0.0035 \\
\hline
\end{tabular}

Table 2 Characteristics of steels mechanical properties.

\begin{tabular}{c|c|c|c}
\hline$E_{a}(\mathrm{MPa})$ & $\sigma_{e}(\mathrm{MPa})$ & $\varepsilon_{u}$ & $\sigma_{r}(\mathrm{MPa})$ \\
\hline \hline 200,000 & 400 & 0.01 & 400 \\
\hline
\end{tabular}

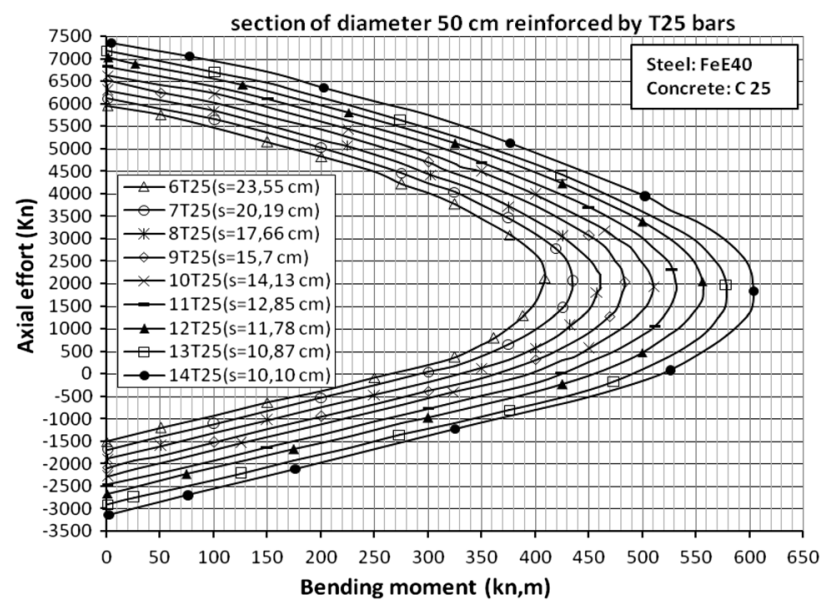

Fig. 7 Abacus giving the number of T25 bars for a circular section. $(D=50 \mathrm{~cm}), f_{c j}=25 \mathrm{MPa}$.

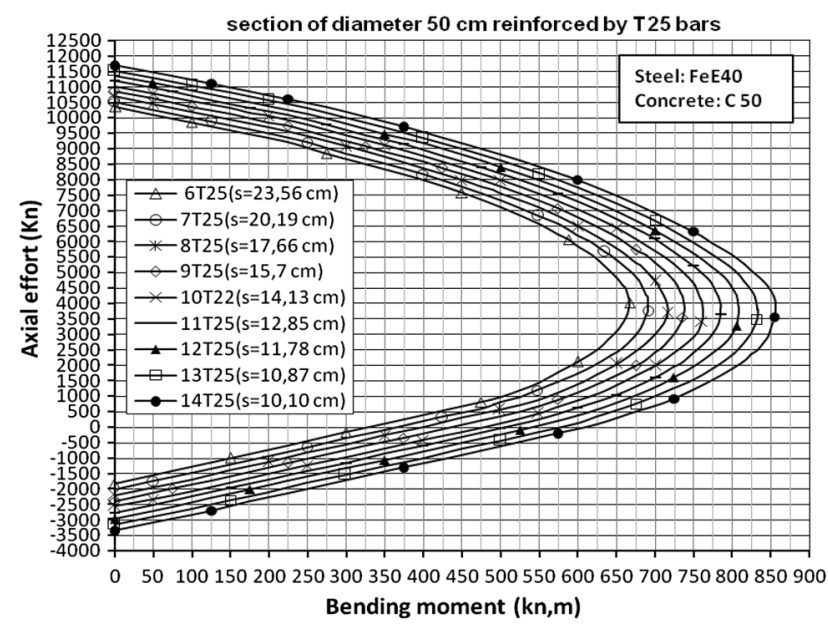

Fig. 8 Abacus giving the number of T25 bars for a circular section. $(D=50 \mathrm{~cm}), f_{c j}=50 \mathrm{MPa}$. 


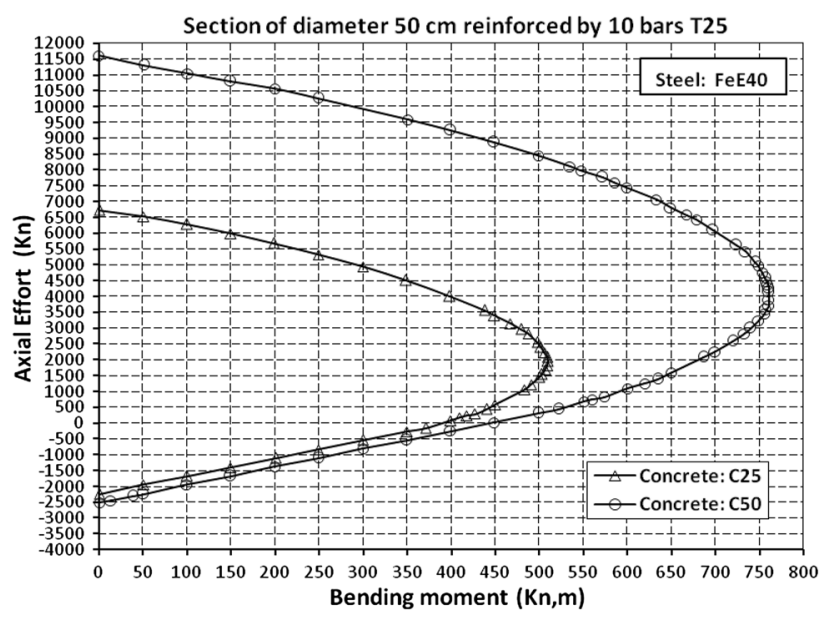

Fig. 9 Influence of the concrete compressive strength.

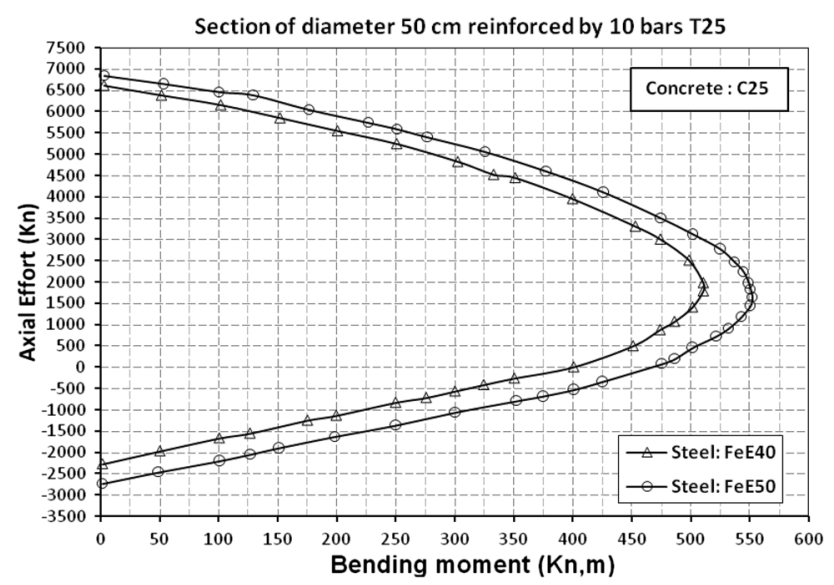

Fig. 10 Superposition of curves (M, N) for both feE40 and feE50 steels.

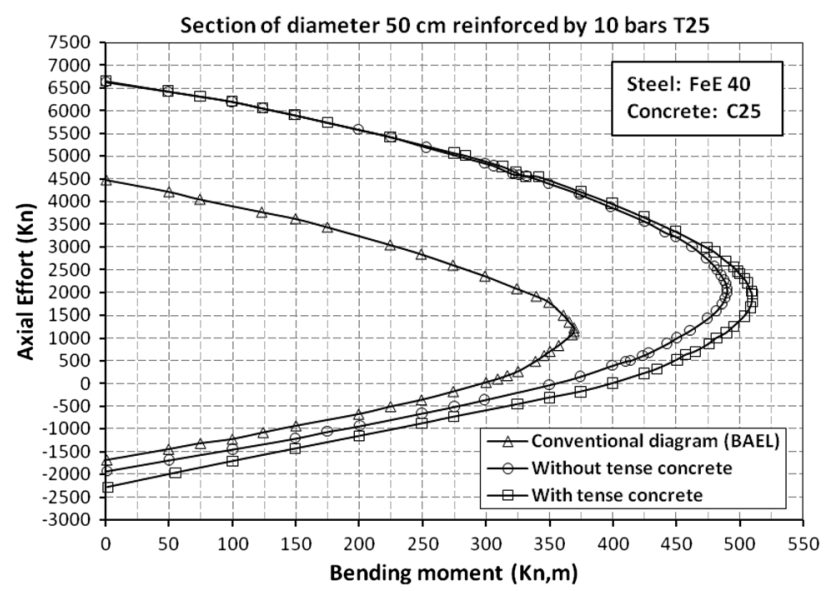

Fig. 11 Influence of taking into account the tense concrete and comparison with BAEL rules.

For the reinforcement bar at order i, the internal forces are expressed by Eq. (11):

$$
\left\{\begin{array}{l}
N_{\text {int }}=A_{a i} \cdot \varphi_{a}\left(\varepsilon_{i}\right) \\
M_{\text {int }}=A_{a i} \cdot \varphi_{a}\left(\varepsilon_{i}\right) \cdot y_{a i}
\end{array}\right.
$$

The Eq. (11) can be written in the matrix form as follows:

$$
\left[\begin{array}{l}
N_{i n t} \\
M_{\text {int }}
\end{array}\right](\delta u, \delta w)=\sum\left[\begin{array}{c}
1 \\
y_{a i}
\end{array}\right] \cdot \varphi_{a}\left(\delta u+\delta w \cdot y_{a i}\right) \cdot A_{a i}
$$

\section{Establishment of Loading Curves}

These curves permit to observe the beam section behavior in nonlinear elasticity until rupture. Of course, it is not possible to represent, directly, on the plan a function with two variables, so the problem is reduced to a single variable. Thus, two representations are possible.

- The first one, it's about to find a $N$ value (axial force), and for any $M i$ value; deformations balancing efforts $(N$, $M i)$. Then the loading curve $M=f(\delta w)$ is deducted.

- The second is to find a $M$ value (bending moment), and for any $\mathrm{Ni}$ value; the deformations balancing efforts $(\mathrm{Ni}$, $M)$. Then the loading curve $N=f(\delta u)$ is deducted. The Flowchart method is given in Fig. 4.

\section{Establishment of the Interaction Curve}

\subsection{Theoretical Explanations}

The behavior curves $N=f(\delta u)$ and $M=f(\delta w)$ pass through a maximum in points $(M, N \max )$ and $(N$, Mmax $)$, respectively. By wearing into the plan, Mmax values for all values of $N$, a curve $N=f(\operatorname{Mmax})$, which is the field limit curve of permissible stresses for the considered section, is obtained. The resulting field is delimited by a curve called the resistance boundary curve for this section (see Fig. 5). The presence of point steel in section induces operator $\Phi$ none derivability points (the operator who allows the passage of deformations to efforts that they develop) in the field of admissible deformations by the transverse section. These Points are characterized by the steels rupture. Either the current deformation of the tense reinforcement, then:

$$
\varepsilon_{a i} \geq-\varepsilon_{u}
$$

\subsection{Calculation Algorithm}

Deformation values are initialized by those that correspond to simple compression $\delta u=\varepsilon_{0}, \delta w=0$ (the limit compression of the section), ending with values $\delta u=\varepsilon_{\mathrm{u}}$, $\delta w=0$; corresponding at steel tensile limit, certainly passing by the composed bending of the section. The method of resolution is given by Fig. 6 .

\section{Application to the Reinforced Concrete}

\subsection{Influence of the Steel Bars Number}

To illustrate the reliability of the program developed in this study, the calculation for a circular section of $50 \mathrm{~cm}$ diameter with steel bars T25 $\left(\phi_{a}=25 \mathrm{~mm}\right)$ is presented. Two 
Table 3 Concrete mechanical properties.

\begin{tabular}{c|c|c|c|c|c|c}
\hline & $f_{c j}(\mathrm{MPa})$ & $f_{t j}(\mathrm{MPa})$ & $E_{b o}(\mathrm{MPa})$ & $\varepsilon_{r t}$ & $\varepsilon_{0}$ & $\varepsilon_{c u}$ \\
\hline \hline BFAC & 47.6 & 2.94 & 38,180 & -0.05 & 0.0021 & 0.0035 \\
\hline BFON & 47.7 & 2.94 & 38,180 & -0.05 & 0.0021 & 0.0035 \\
\hline
\end{tabular}

Table 4 Fibers mechanical properties.

\begin{tabular}{c|c|c|c|c|c|c}
\hline & $L_{f}(\mathrm{~mm})$ & $w(\%)$ & Diameter $(\mathrm{mm})$ & $E_{a}(\mathrm{MPa})$ & $\varepsilon_{u}$ & Configuration \\
\hline \hline BFAC & 60 & 0.31 & 1 & 200,000 & 0.074 & Hooked fibers \\
\hline BFON & 60 & 0.31 & 1 & 200,000 & 0.074 & Undulated fibers \\
\hline
\end{tabular}

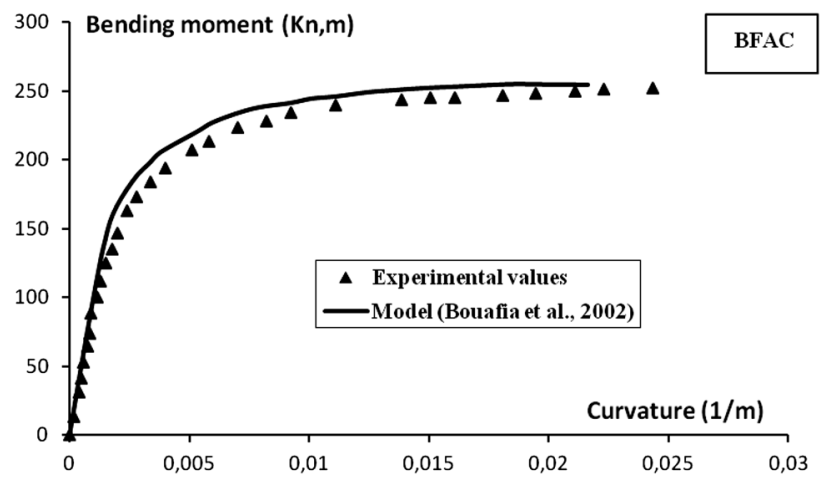

Fig. 12 Comparison of calculation with experimental results (BFAC).

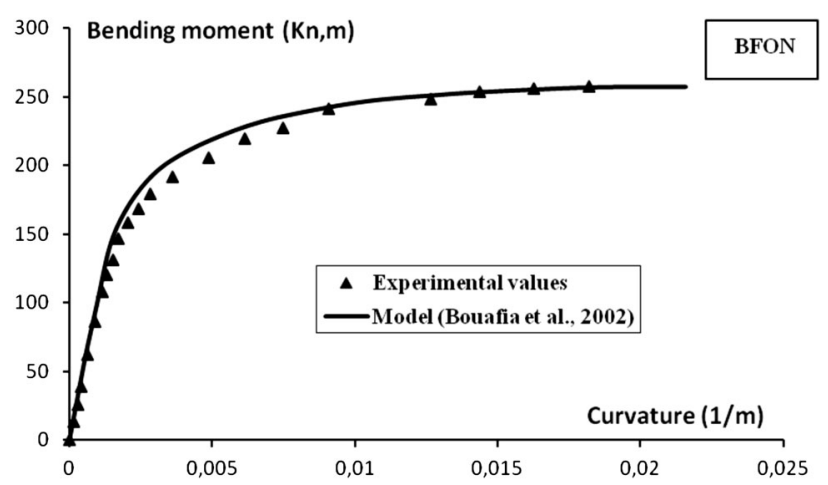

Fig. 13 Comparison of calculation with experimental results (BFON).

classes of concrete strength, C25 and C50 are used and their main characteristics are summarized in Tables 1 and 2. Also, the real behavior laws for concrete and steel were adopted.

Figures 7 and 8 represent interaction axial effort $N$ and bending moment $M$ curves for two classes of the concrete: $\mathrm{C} 25$ and C50. For values of $N$ and $M$ known, the number of bars is directly read on these abacuses.

\subsection{Influence of Concrete Strength Characteristics}

For the same section of diameter $50 \mathrm{~cm}$ reinforced with T25 bars; the calculation, while varying the concrete characteristic of 25 and $50 \mathrm{MPa}$, has been performed. Curves obtained (with 10 bars of diameter $\phi_{a}=25 \mathrm{~mm}$ ) for the two resistances are superposed on Fig. 9.

The difference between the two curves is important in the compressions field. Indeed, the influence of the concrete resistance is felt at the compression level; behavior in compression is described by the Sargin law. But the contribution in traction remains weak; the concrete tensile strength is the order of tenth of its compression resistance.

\subsection{Influence of the Steel Yield Stress}

Calculation is carried out for two yield stresses (400 and $500 \mathrm{MPa}$ ). The superposition is given in the Fig. 10. There is a translation of the curve due to the symmetrical behavior of steel.

\subsection{Influence of the Tense Concrete Participation}

The contribution of the tense concrete still low compared to the all section behavior. Compared to the calculation without tense concrete, its influence is much felt, rather, in the case of simple bending (see Fig. 11).

\subsection{Comparing the Behavior According to the Conventional Relationships (BAEL)}

Figure 11 shows the curves, normal force versus bending moment, for the values from a conventional calculation (BAEL) for the calculated values without taking into account tense concrete and for the values with tense concrete. The comparison of these curves clearly shows the corresponding surface to the introduction of safety factors considered in the conventional calculations.

\section{Application to Steel Fibers Reinforced Concrete}

\subsection{Confrontation with Experimental Results}

The nonlinear modeling of the circular section, considered in this work, was validated on piles whose experimental

Table 5 Characteristics of mechanical properties of fibers under study.

\begin{tabular}{c|c|c|c|c|c|c}
\hline$L_{f}(\mathrm{~mm})$ & $w(\%)$ & Diameter $(\mathrm{mm})$ & $E_{a}(\mathrm{MPa})$ & $\sigma_{e}(\mathrm{MPa})$ & $\varepsilon_{u}$ & Configuration \\
\hline \hline 30,50 & $0.5,1,1.5$ & 1 & 200,000 & 1100 & 0.074 & With hook \\
\hline
\end{tabular}




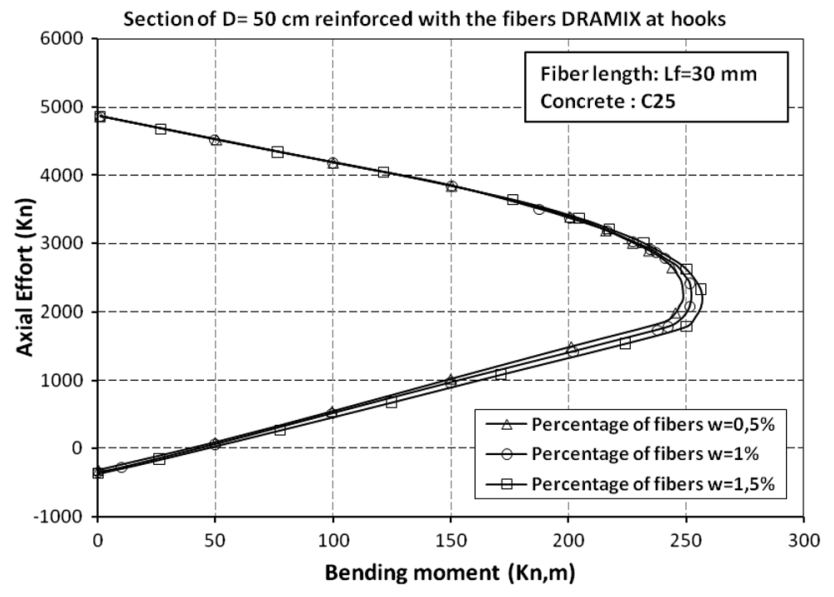

Fig. 14 Circular section $(D=50 \mathrm{~cm})$ reinforced with steel fibers in length $l_{f}=30 \mathrm{~mm}$.

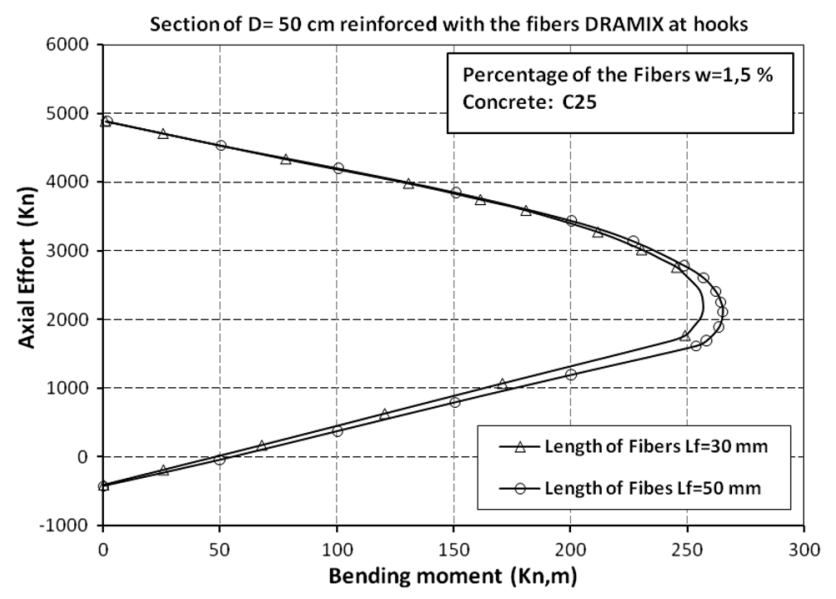

Fig. 15 Influence of the fiber length.

study is performed at CEBTP (Zhang 1991). The Sargin law is used to describe the fiber reinforced concrete compression behavior. The relations proposed by Bouafia et al. (2002) were used for traction.

The piles have a diameter of $500 \mathrm{~mm}$ and are subject to combined bending. The normal compression force is $1370 \mathrm{kN}$ (applied using external prestressing). The first type of piles is hooks fibers reinforced; it is noted BFAC. The second type of piles is reinforced by corrugated fibers; it is noted BFON. The same percentage of fibers is used $(0.31 \%$ by volume). The mechanical properties of concrete and fiber are given, respectively, in Tables 3 and 4. The comparison of calculation with experimental results is shown in Figs. 12 and 13.

The test/calculation ratio is close to 1 in the case of the bending moment. Against by, in the case of ultimate curves, this ratio varies between 0.90 and 1.09 . This may be due to using the tangent method to the resolution; it sometimes has some convergence problems in the vicinity of the maximum curve. However, the calculation is satisfactory for a percentage of fiber equal to $0.31 \%$.

\subsection{Confrontation Between Reinforced and Steel Fibers Concrete}

Fibers studied are provided with hooks, type "DRAMIX", their main characteristics are described in Table 5. Behavior

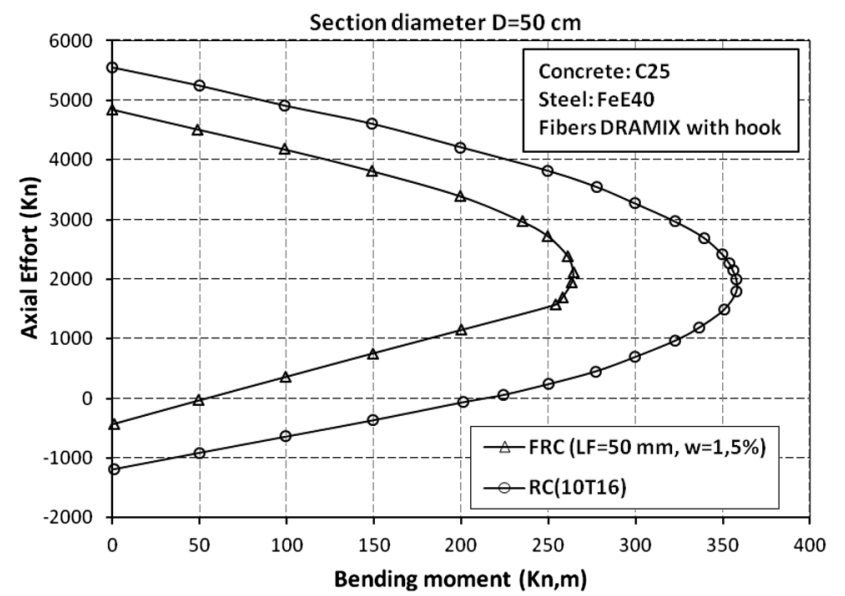

Fig. 16 Comparison of the reinforced concrete section (RC) and the fiber reinforced concrete section (FRC).

curves are calculated for two fiber lengths (30 and $50 \mathrm{~mm}$ ) and three percentages $(0.5-1$ and $1.5 \%)$. Results and comparisons between different parameters are given in Figs. 14, 15 and 16.

\subsection{Discussion}

The percentage of fibers positively influences the steel fibers reinforced section behavior; this contribution of resistance is more important in bending and in tension, unlike in the compression. Curves (Fig. 14) show clearly that the allowable compressive stress remains unchanged with fibers percentage variation, this confirms that the steel fibers are rather effective in traction.

The fiber length slightly increases resistance: the length of anchoring thereof in the concrete mass is greater. It then enables better sewing the crack.

By cons, it is not a substitute compared to traditional reinforcement in structural elements (see Fig. 16). However, they are used in thin and slabs elements and also to the strengthening and repair (in the form of the shotcrete).

\section{Conclusion}

The developed software allows to draw abacuses directly giving the bars number necessary to implementing according to the external forces applied and thus to predict the breaking of circular sections. Indeed, the calculation is often tedious for this type of sections. In addition, the calculation methods are often approached. The presented method in this paper uses the actual behavior of different materials (concrete, steel and fiber concrete).

A confrontation is performed with respect to the calculation according to BAEL rules, showing the influence of safety factors. The influence of the fibers is also taken into account. Finally, a confrontation between the reinforced concrete and the fiber concrete (in equivalent percentage) shows the importance and necessity to use steel rebar. 
The interest of the developed program is the ability to modify a number of parameters while getting quickly results, this allows studying any section. Therefore, it may be a very practical tool for engineers calculators seen its ease of use.

\section{Open Access}

This article is distributed under the terms of the Creative Commons Attribution 4.0 International License (http://creativecommons.org/licenses/by/4.0/), which permits unrestricted use, distribution, and reproduction in any medium, provided you give appropriate credit to the original author(s) and the source, provide a link to the Creative Commons license, and indicate if changes were made.

\section{References}

Adjrad, A., Bouafia, Y., Kachi, M. S., \& Dumontet, H. (2015). Modeling of externally prestressed beams until fracture in non linear elasticity. Applied Mechanics and Materials, 749, 379-385.

Bonet, J. L., Baros, M. H. F. M., \& Romero, M. L. (2006). Comparative study of analytical and numerical algorithms for designing reinforced concrete sections under biaxial bending. Computers \& Structures, 84, 2184-2193.

Bouafia, Y., Kachi, M.S., \& Fouré, B. (2000). Numerical modeling of the behavior of steel fiber reinforced concrete. In Proceedings of the II international conference on cement and concrete technology in the 2000s (Vol. 2, pp. 582-591) Istanbul, Turkey.

Bouafia, Y., Kachi, M.S. \& Fouré, B. (2002). Relation stressstrain in the case of steel fiber reinforced concrete. In ESKA (Eds. Annales of ITB), No 3.

Choa, C. G., \& Kwonb, M. (2008). Prediction of non linear bending behavior for FRP Concrete beams based on multiaxial constitutive laws. Engineering Structures, 30, 2311-2320.

Daunys, M., \& Rimovkis, S. (2006). Analysis of circular crosssection element, loaded by static and cyclic elastic-plastic pure bending. International Journal of Fatigue, 28, 211-222.

Ding, Y., Zhang, F., Torgal, F., \& Zhang, Y. (2012). Shear behavior of steel fibre reinforced self-consolidating concrete beams Based on the modified compression field theory. Composite Structures, 94, 2440-2449.
Eurocode 2. (1992). Design of concrete structures Part 1-1: General rules and rules for buildings. ENV 1992-1-1, NF P 18711.

Grelat, A. (1978). Nonlinear behavior and stability of indeterminate reinforced concrete frames, Doctoral thesis, University Paris VI, Paris, France.

Islam, M. S., \& Shahria, A. (2013). Principal component and multiple regression analysis for steel fiber reinforced concrete (SFRC) beams. International Journal of Concrete Structures and Materials, 7(4), 303-317.

Kachi, M. S., Bouafia, Y., Saad, M., Dumontet, H., \& Bouhrat, S. (2014). Contribution to the calculation of reinforced concrete circular sections by discrete reinforcement. International Journal of Engineering and Technology, 6(1), $38-42$.

Liang, Q. Q., \& Fragomeni, S. (2009). Non linear analysis of circular concrete-filled steel tubular short columns under axial loading. Journal of Constructional Steel Research, 65, 2186-2196.

Özcan, D. M., Bayraktar, A., Sahin, A., Haktanir, T., \& Türker, T. (2009). Experimental and finite element analysis on the steel fiber-reinforced concrete (SFRC) beams ultimate behavior. Construction and Building Materials, 23, 1064-1077.

Ren, W., Sneed, L. H., Gai, Y., \& Kang, X. (2015). Test results and nonlinear analysis of RC T-beams strengthened by bonded steel plates. International Journal of Concrete Structures and Materials., 9(2), 133-143.

Ronagh, H. R., \& Baji, H. (2014). On the FE modeling of FRPretrofitted beam-column subassemblies. International Journal of Concrete Structures and Materials, 8(2), 141-155.

Rules: BAEL91 revised 99, technical design rules and calculation of works and structures reinforced concrete, according to the limit states method.

Sorensen, C., Berge, E., \& Nikolaisen, E. B. (2014). Investigation of fiber distribution in concrete batches discharged from ready-mix truck. International Journal of Concrete Structures and Materials, 8(4), 279-287.

Tadepalli, P. R., Dhonde, H. B., Mo, Y. L., \& Hsu, T. T. C. (2015). Shear strength of prestressed steel fiber concrete I-beams. International Journal of Concrete Structures and Materials, 9(3), 267-281.

Zhang, Z. (1991). Contribution to the dimensioning of reinforced concrete piles fibers, Doctoral thesis. University of Orléans, Orléans, France. 